\title{
Industrial vegetable oil by-products increase the ductility of polylactide
}

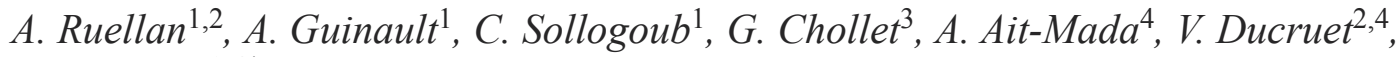 \\ S. Domenek ${ }^{2,4 *}$ \\ ${ }^{1}$ PIMM, Arts et Métiers ParisTech/CNRS/CNAM, 151 Bd de l'Hôpital, F-75013 Paris Cedex, France \\ ${ }^{2}$ AgroParisTech, UMR1145 Ingénierie Procédés Aliments, 1 rue des Olympiades, F-91300 Massy, France \\ ${ }^{3}$ ITERG, Lipochimie Hall Industriel, 11 rue Monge, F-33600 Pessac, France \\ ${ }^{4}$ INRA, UMR1145 Ingénierie Procédés Aliments, 1 rue des Olympiades, F-91300 Massy, France
}

Received 15 June 2015; accepted in revised form 26 July 2015

\begin{abstract}
The use of industrial by-products of the vegetable oil industry as ductility increasing additives of polylactide (PLA) was investigated. Vegetable oil deodorization condensates were melt-blended by twin-screw extrusion up to a maximum inclusion quantity of $20 \mathrm{wt} \%$ without preliminary purification. Sample films were obtained by single screw cast extrusion. Compounded PLA films featured largely improved ductility in tensile testing with an elongation at break up to $180 \%$. The glass transition temperature remained higher than room temperature. The native mixture of molecules, which composed the deodorization condensates, had superior performance compared to a synthetic mixture of main compounds. The investigation of the correlation between composition of the additives and the ductility of the PLA blends by Principal Component Analysis showed synergy in property improvement between fatty acids having a melting point below and beyond the room temperature. Furthermore, a compatibilizing effect of molecules present in the native mixture was evidenced. Oil deodorization condensates, which are a price competitive by-product of the vegetable oil industry, are therefore a very promising biobased and biodegradable additive for improving the ductility of PLA.
\end{abstract}

Keywords: biodegradable polymers, poly(lactic acid), ductility, vegetable oil by-products, crazing

\section{Introduction}

Biodegradable and/or biobased polymers are widely studied to replace petroleum-based materials with the aim of contributing to higher sustainability of plastics. However, in many cases these new products still do not meet economical or functional requirements to be competitive in commodity applications. Polylactide (PLA) is one of the polymers which can potentially enter high volume markets, mostly in the food packaging [1-3] or textile [4] sector. Polylactide is a biobased and compostable polymer [5-7] issued from polymerization of lactic acid produced by fermentation of starch, potatoes or beets [7, 8]. Although it has been known before [9], production cost reduction in the 1990s and 2000s thanks to breakthroughs in the polymerization technology $[10,11]$, made it economically competitive with petroleum-based materials. PLA offers many interests such as a glass transition higher than room temperature, ease of processing, high transparency, printability, glossy aspect $[1,12,13]$. However, its mechanical properties still remain an obstacle for many applications. In fact, PLA features high tensile strength and modulus but also high brittleness [14]. In order to enhance the PLA ductility, melt-blending with rubbery materials as poly(ether)urethane [15,

\footnotetext{
${ }^{*}$ Corresponding author, e-mail: sandra.domenek@agroparistech.fr (C) BME-PT
} 
16], polyamide elastomer [17], acrylonitrile-butadiene-styrene copolymer, or various impact modifiers [18-26] is effective. Furthermore, plasticizers such as citrate esters [27-37], polyethylene glycols [27,33, 38-44] or manifold other molecules [29, 43, 45-48] can be used. Unfortunately, impact modifiers are often not biodegradable nor biobased and plasticizers are generally derived from fossil resources, degrading one important environmental advantage of employing PLA. Therefore biobased and biodegradable additives have been and are investigated for toughening PLA. Chemically modified vegetable oils have received important research interest, because ester or epoxy groups can be degraded by microorganisms [49], maintaining the biodegradability of blends with PLA. Polymerized soybean oil derivatives prepared by crosslinking double bonds of alkyl chains afforded ductility increase after meltblending with PLA and using a compatibilizer [50]. Improvements were also obtained with conjugated soybean oil which was reactively compatibilized with PLA by unsaturated triglycerides [51]. Epoxidized soybean oil [52-55] and epoxidized palm oil [56-58] also showed some positive effects on PLA toughness. Another approach consists in using rigid particles, which usually increased stiffness but is ineffective, or even detrimental for the ductility. Nonetheless, NatureWorks [59] reported the use of EMforce ${ }^{\circledR}$, a mineral additive, able to change the polymer failure mode from brittle to ductile. In fact, the efficient crack initiation in glassy PLA, which was provided by the well-dispersed additive with good interfacial adhesion to the matrix, enhanced the PLA elongation at break.

Expertise from plasticizing polyvinylchloride teaches that mixtures of different plasticizers are efficient for increasing toughness, because they make use of different mechanisms available for ductility improvement [49]. For example, a mixture of tributyl citrate (TBC) and a block copolymer PLA-g-polyethyleneglycol yielded a material with high elongation at break and satisfying stress at yield [30]. Al-Mulla et al. [55] successfully used modified nanoclays in combination with epoxidized soybean oil to increase stiffness and ductility. The combination of PLA with rubber and compatibilizers has also been investigated by several authors, showing important gains in ductility, with an elongation at break of up to $160 \%$ for high rubber concentrations [60] or bicontinous phases [61], and up to $200 \%$ when using compatibilizers $[62,63]$. However, these solutions often require the inclusion of several additives, chemically modified and costly components that increase the price of the final formulation, which is inappropriate for a large volume production. Finding a low cost biobased and biodegradable toughening agent would therefore help PLA to conquer new markets.

Vegetable oils contain a number of potentially interesting molecules for PLA toughening and the refinery of vegetable oils gives rise to several by-products. Among those, oil deodorization condensates represent a high-volume by-product, which is chemically close to the vegetable oil. They are obtained by distillation in the aim of purifying the raw oil from odorous compounds, which are negative for the sensorial properties of vegetable oils. Deodorization condensates contain free fatty acids, glycerides and unsaponifiable molecules. The objective of this study was to use vegetable oils and the byproduct deodorization condensate as produced for toughening PLA. The individual molecules which make up oils and deodorization condensates were tested on the mechanical properties and several vegetable oils were screened.

\section{Experimental}

\subsection{Materials}

PLA 4060D was supplied by NatureWorks (U.S.A.) and consists of $89 \pm 1 \%$ L-lactic acid and $11 \pm 1 \%$ Dlactic acid units, making it unable to crystallize under common conditions $[1,64]$. The glass transition temperature $\left(T_{\mathrm{g}}\right)$ obtained from differential scanning calorimetry (DSC) measurements was $56^{\circ} \mathrm{C}$. Average molecular weights obtained from size exclusion chromatography (SEC) measurements were $M_{\mathrm{W}}=236800 \mathrm{~g} \cdot \mathrm{mol}^{-1}, M_{\mathrm{n}}=103700 \mathrm{~g} \cdot \mathrm{mol}^{-1}$ and dispersity $M_{\mathrm{w}} / M_{\mathrm{n}}=2,28$.

Hydrogenated palm oil (HPO), Hydrogenated Copra Oil (HCO), Rapeseed Oil Deodorization Condensate (RODC), Soybean Oil Deodorization Condensate (SODC), Olive Oil Deodorization Condensate (OODC) and Palm Oil Deodorization Condensate (PODC) were supplied by ITERG (Bordeaux, France).

Palmitic acid (purity $>98 \%$ ) i.e. hexadecanoic acid (C16:0), oleic acid (purity $>96 \%$ ) i.e. 9-octadecenoic acid (C18:1), squalene (purity $>98 \%$ ) i.e. (6E,10E,14E,18E)-2,6,10,15,19,23-hexamethyltetracosa-2,6,10,14,18,22-hexaene, and alpha-toco- 
pherol (purity $>96 \%$ ) i.e. (2R)-2,5,7,8-tetramethyl2-[(4R,8R)-(4,8,12-trimethyltridecyl)]-6-chromanol, were supplied by Sigma-Aldrich (France).

\subsection{Film fabrication}

Prior to melt-blending, PLA pellets were dried at $60^{\circ} \mathrm{C}$ for $24 \mathrm{~h}$ under dried air using a SOMOS 60L. Relative humidity of dried pellets was controlled to be lower than 350 ppm using an Aboni FMX Hydrotracer (France). Melt-mixing of PLA with or without additives was carried out using a twin screw extruder (Thermo Haake Ptw 16-40D, France), having a screw diameter of $16 \mathrm{~mm}$ and a length to diameter ratio $(L / D) 40: 1$. A temperature of $180^{\circ} \mathrm{C}$ was used to process by twin-screw extrusion the PLA pellets as reference material, while the temperature profile of the 7 heating zones decreased from 180 to about $150 / 130^{\circ} \mathrm{C}$ along the extrusion flow, depending on the nature and the amount of additive. Screw speed was $300 \mathrm{rpm}$. The exact temperature profile for each formulation is given in Table 1. To properly control the feed rate of additives, which are solid at room temperature, a home-made apparatus consisting in a heated syringe was used. Obtained pellets were stored into hermetic sealed metalized bags to avoid PLA rehydration.

Films of about $0.8 \mathrm{~mm}$ thickness containing palmitic acid, oleic acid, hydrogenated palm oil, hydrogenated copra oil, squalene, $\alpha$-tocopherol and some combinations of these products were obtained using a single screw extruder (Scamex Rheoscam, France), mounted with a screw of $20 \mathrm{~mm}$ diameter and a length to diameter ratio $(L / D) 12: 1$ and a flat die of $40 \mathrm{~mm}$ width and $1 \mathrm{~mm}$ thickness. Films were stretched and cooled with chill rolls. Due to the short length of the screw, an increasing temperature profile from 180 to $195^{\circ} \mathrm{C}$ over the 3 heating zones was used for PLA, while it was decreasing from 180

Table 1. Processing conditions of melt-mixing twin screw extrusion

\begin{tabular}{|c|c|c|}
\hline & Formulation & $\begin{array}{c}\text { Temperature profile } \\
{\left[{ }^{\circ} \mathrm{C}\right]}\end{array}$ \\
\hline Neat PI & & $175 / 180 / 190 / 190 / 190 / 190 / 180$ \\
\hline PLA + & $0 \mathrm{wt} \% \mathrm{C} 16: 0$ & $175 / 180 / 180 / 170 / 170 / 170 / 170$ \\
\hline PLA + & $0 \mathrm{wt} \% \mathrm{C} 18: 1$ & $175 / 180 / 180 / 170 / 170 / 170 / 170$ \\
\hline PLA + & $0 \mathrm{wt} \%[50 \mathrm{wt} \% \mathrm{C} 16: 0+50 \mathrm{wt} \% \mathrm{C} 18: 1]$ & $175 / 180 / 180 / 170 / 170 / 170 / 170$ \\
\hline PLA + & $0 \mathrm{wt} \%[95 \mathrm{wt} \%(50 \mathrm{wt} \% \mathrm{C} 16: 0+50 \mathrm{wt} \% \mathrm{C} 18: 1)+5 \mathrm{wt} \% \mathrm{HPO}]$ & $175 / 180 / 180 / 170 / 170 / 170 / 170$ \\
\hline PLA + & \begin{tabular}{|l}
$5 \mathrm{wt} \% \mathrm{HCO}$ \\
$10 \mathrm{wt} \% \mathrm{HCO}$ \\
$15 \mathrm{wt} \% \mathrm{HCO}$
\end{tabular} & $\begin{array}{l}175 / 180 / 180 / 180 / 180 / 170 / 170 \\
175 / 180 / 180 / 180 / 180 / 170 / 170 \\
175 / 180 / 180 / 180 / 170 / 170 / 160\end{array}$ \\
\hline PLA + & $\begin{array}{l}5 \mathrm{wt} \% \mathrm{HPO} \\
10 \mathrm{wt} \% \mathrm{HCO} \\
15 \mathrm{wt} \% \mathrm{HCO}\end{array}$ & $\begin{array}{l}175 / 180 / 180 / 180 / 180 / 170 / 170 \\
175 / 180 / 180 / 180 / 180 / 170 / 170 \\
175 / 180 / 180 / 180 / 180 / 170 / 170\end{array}$ \\
\hline PLA + & $\begin{array}{l}5 \mathrm{wt} \% \alpha \text {-tocopherol } \\
10 \mathrm{wt} \% \alpha \text {-tocopherol } \\
15 \mathrm{wt} \% \alpha \text {-tocopherol }\end{array}$ & $\begin{array}{l}175 / 180 / 180 / 180 / 180 / 180 / 180 \\
175 / 180 / 180 / 180 / 180 / 180 / 170 \\
175 / 180 / 180 / 180 / 180 / 170 / 170\end{array}$ \\
\hline PLA + & $\begin{array}{l}5 \mathrm{wt} \% \text { squalene } \\
10 \mathrm{wt} \% \text { squalene } \\
15 \mathrm{wt} \% \text { squalene }\end{array}$ & $\begin{array}{l}175 / 180 / 180 / 180 / 180 / 180 / 180 \\
175 / 180 / 180 / 180 / 180 / 170 / 170 \\
175 / 180 / 180 / 180 / 180 / 170 / 170\end{array}$ \\
\hline PLA + & $\begin{array}{l}5 \mathrm{wt} \% \text { RODC } \\
10 \mathrm{wt} \% \text { RODC } \\
15 \mathrm{wt} \% \text { RODC } \\
20 \mathrm{wt} \% \text { RODC }\end{array}$ & $\begin{array}{l}175 / 180 / 180 / 180 / 180 / 175 / 170 \\
175 / 180 / 180 / 180 / 180 / 170 / 160 \\
175 / 180 / 180 / 180 / 180 / 170 / 160 \\
175 / 180 / 180 / 180 / 170 / 160 / 150\end{array}$ \\
\hline PLA + & $\begin{array}{l}5 w t \% \text { SODC } \\
10 w t \% \text { SODC } \\
15 w t \% \text { SODC } \\
20 w t \% \text { SODC }\end{array}$ & $\begin{array}{l}175 / 180 / 180 / 180 / 180 / 175 / 170 \\
175 / 180 / 180 / 180 / 180 / 170 / 160 \\
175 / 180 / 180 / 180 / 180 / 170 / 160 \\
175 / 180 / 180 / 180 / 170 / 160 / 150\end{array}$ \\
\hline PLA + & $\begin{array}{l}5 w t \% \text { OODC } \\
10 w t \% \text { OODC } \\
15 w t \% \text { OODC } \\
20 w t \% \text { OODC }\end{array}$ & $\begin{array}{l}175 / 180 / 180 / 170 / 170 / 170 / 170 \\
175 / 180 / 180 / 170 / 170 / 170 / 170 \\
175 / 180 / 180 / 170 / 170 / 160 / 160 \\
175 / 180 / 180 / 170 / 160 / 150 / 150\end{array}$ \\
\hline PLA + & $\begin{array}{l}5 w t \% \text { PODC } \\
10 w t \% \text { PODC } \\
15 w t \% \text { PODC } \\
20 w t \% \text { PODC }\end{array}$ & $\begin{array}{l}175 / 180 / 180 / 180 / 180 / 175 / 170 \\
175 / 180 / 180 / 180 / 170 / 160 / 155 \\
175 / 180 / 180 / 180 / 170 / 160 / 150 \\
175 / 180 / 180 / 170 / 160 / 150 / 135\end{array}$ \\
\hline
\end{tabular}


Table 2. Processing conditions of cast films extrusion

\begin{tabular}{|c|c|c|c|}
\hline & Formulation & $\begin{array}{c}\text { Temperature profile } \\
{\left[{ }^{\circ} \mathrm{C}\right]}\end{array}$ & $\begin{array}{c}\text { Die temperature } \\
{\left[{ }^{\circ} \mathrm{C}\right]}\end{array}$ \\
\hline Neat PI & & $180 / 190 / 195$ & 185 \\
\hline PLA + & $10 \mathrm{wt} \% \mathrm{C} 16: 0$ & $180 / 180 / 175$ & 170 \\
\hline PLA + & $10 \mathrm{wt} \% \mathrm{C} 18: 1$ & $180 / 180 / 175$ & 170 \\
\hline PLA + & $10 \mathrm{wt} \%[50 \mathrm{wt} \% \mathrm{C} 16: 0+50 \mathrm{wt} \% \mathrm{C} 18: 1]$ & $180 / 180 / 175$ & 170 \\
\hline PLA + & $10 \mathrm{wt} \%[95 \mathrm{wt} \%(50 \mathrm{wt} \% \mathrm{C} 16: 0+50 \mathrm{wt} \% \mathrm{C} 18: 1)+5 \mathrm{wt} \% \mathrm{HPO}]$ & $180 / 180 / 175$ & 170 \\
\hline PLA + & $\begin{array}{l}5 \mathrm{wt} \% \mathrm{HCO} \\
10 \mathrm{wt} \% \mathrm{HCO} \\
15 \mathrm{wt} \% \mathrm{HCO}\end{array}$ & $\begin{array}{l}180 / 180 / 180 \\
180 / 170 / 170 \\
180 / 170 / 170\end{array}$ & $\begin{array}{l}180 \\
170 \\
170\end{array}$ \\
\hline PLA + & $\begin{array}{l}5 \mathrm{wt} \% \text { HPO } \\
10 w t \% \text { HPO } \\
15 w t \% \text { HPO }\end{array}$ & $\begin{array}{l}180 / 180 / 180 \\
180 / 170 / 170 \\
180 / 170 / 170\end{array}$ & $\begin{array}{l}170 \\
170 \\
170\end{array}$ \\
\hline PLA + & $\begin{array}{l}5 \mathrm{wt} \% \alpha \text {-tocopherol } \\
10 \mathrm{wt} \% \alpha \text {-tocopherol } \\
15 \mathrm{wt} \% \alpha \text {-tocopherol }\end{array}$ & $\begin{array}{l}180 / 180 / 180 \\
180 / 180 / 180 \\
180 / 175 / 170\end{array}$ & $\begin{array}{l}180 \\
180 \\
170\end{array}$ \\
\hline PLA + & $\begin{array}{l}5 \mathrm{wt} \% \text { squalene } \\
10 \mathrm{wt} \% \text { squalene } \\
15 \mathrm{wt} \% \text { squalene }\end{array}$ & $\begin{array}{l}180 / 180 / 180 \\
180 / 180 / 175 \\
180 / 180 / 170\end{array}$ & $\begin{array}{l}180 \\
170 \\
170\end{array}$ \\
\hline
\end{tabular}

to about $170^{\circ} \mathrm{C}$ for blends. The specific temperatures depending on the nature and the amount of additive are given in Table 2.

In the case of the deodorization condensates of the vegetable oils (RODC, SODC, OODC, PODC), the available quantity was insufficient for carrying out a single screw extrusion in the aim to obtain films. In that case PLA sheets of $1 \mathrm{~mm}$ thickness were thermo-moulded by compression at 220 bar (Laboratory Press Gibitre Instruments 20 tons, Italy). For this, pellets were pre-melted at $180^{\circ} \mathrm{C}$ without pressure during 180 seconds then heating plates were closed with progressive increase in pressure during 120 seconds to eliminate air bubbles.

\subsection{Chemical and physical chemical characterization of vegetable oils and deodorization condensates}

Glyceride composition of fats was determined according to the IUPAC 6.002 and EN 14105 standards using a Shimadzu GC-2010 Plus gas chromatograph (France) equipped with a Zebron ZB 5 HT Inferno $(15 \mathrm{~m}, 0.25 \mathrm{~mm}, 0.1 \mu \mathrm{m})$ column and a flame ionization detector set at $380^{\circ} \mathrm{C}$. The vector gas was $\mathrm{H}_{2}$ at a flow rate of $1.17 \mathrm{~mL} \cdot \mathrm{min}^{-1}$. Both the injector and the oven temperature were set at $60^{\circ} \mathrm{C}$ for $3 \mathrm{~min}$, then raised to $370^{\circ} \mathrm{C}$ at $10^{\circ} \mathrm{C} \cdot \mathrm{min}^{-1}$ and held at $370^{\circ} \mathrm{C}$ for $12 \mathrm{~min}$. Direct on-column injection was performed.

Fatty acid composition was determined according to the ISO 12966-2 standard using a Shimadzu GC-
2010 Plus gas chromatograph (France) equipped with a BPX70 $(50 \mathrm{~m}, 0.22 \mathrm{~mm}, 0.25 \mu \mathrm{m})$ column, and a flame ionization detector set at $250^{\circ} \mathrm{C}$. The vector gas was $\mathrm{H}_{2}$ at a flow rate of $0.32 \mathrm{~mL} \cdot \mathrm{min}^{-1}$. The oven temperature was set at $60 \mathrm{C}$ for $2 \mathrm{~min}$, raised to $170^{\circ} \mathrm{C}$ at $20^{\circ} \mathrm{C} \cdot \mathrm{min}^{-1}$, held at $170^{\circ} \mathrm{C}$ for $25 \mathrm{~min}$, raised to $230^{\circ} \mathrm{C}$ at $4^{\circ} \mathrm{C} \cdot \mathrm{min}^{-1}$ and held at $230^{\circ} \mathrm{C}$ for $10 \mathrm{~min}$. The injector temperature was set at $250^{\circ} \mathrm{C}$ and a split ratio of 200 was used.

Acid value was determined according to the ISO 660 standard using a mixture of ethanol $95 \%$ and diethylic ether as solvent, potassium hydroxide $0.5 \mathrm{~mol} \cdot \mathrm{L}^{-1}$ in ethanol $95 \%$ as titrant and alkali blue $6 \mathrm{~B}$ as indicator.

Saponification value was determined according to the ISO 3657 standard. Samples were saponified with potassium hydroxide $0.5 \mathrm{~mol} \cdot \mathrm{L}^{-1}$ in ethanol $95 \%$ boiled under reflux during $2 \mathrm{~h}$. Hydrochloric acid $0.5 \mathrm{~mol} \cdot \mathrm{L}^{-1}$ was used as titrant and alkali blue $6 \mathrm{~B}$ as indicator.

Water content was measured using a Mettler Toledo HB43 S Halogen Moisture Analyzer set (France) at $103^{\circ} \mathrm{C}$.

Melting point of free fatty acids was determined from literature [65]. Estimation of mono, di- and triglycerides average chemical structure of oil deodorization condensates was based on the averages unsaturation number and the alkyl chains length of the corresponding free fatty acids composition profile (Table 3). Average glycerides melting point was estimated calculating a weighted average of the 
Table 3. Composition of hydrogenated vegetable oils and vegetable oil deodorization condensates

\begin{tabular}{|c|c|c|c|c|c|c|c|c|}
\hline Type & & & HPO & HCO & RODC & SODC & OODC & PODC \\
\hline \multirow{7}{*}{ 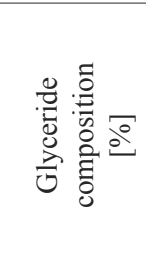 } & \multicolumn{2}{|l|}{ Free fatty acids } & 0.0 & 0.0 & 39.0 & 43.1 & 39.2 & 95.4 \\
\hline & \multicolumn{2}{|l|}{ Monoglycerides } & 0.2 & 0.0 & 11.2 & 2.9 & 2.0 & 1.7 \\
\hline & \multicolumn{2}{|l|}{ Diglycerides } & 10.6 & 0.0 & 2.7 & 9.0 & 8.4 & 2.2 \\
\hline & \multicolumn{2}{|l|}{ Triglycerides } & 88.9 & 100 & 12.2 & 16.8 & 33.5 & 0.7 \\
\hline & \multicolumn{2}{|c|}{ Sterols ( $\alpha$-tocopherol) } & 0.0 & 0.0 & 25.7 & 9.8 & 1.6 & 0.0 \\
\hline & \multicolumn{2}{|c|}{ Hydrocarbons (Squalene) } & 0.0 & 0.0 & 0.0 & 13.8 & 13.0 & 0.0 \\
\hline & \multicolumn{2}{|c|}{ Unidentified } & 0.3 & 0.0 & 9.2 & 4.6 & 2.3 & 0.0 \\
\hline \multirow{3}{*}{\multicolumn{3}{|c|}{$\begin{array}{l}\text { Acid value }\left[\mathrm{mg} \mathrm{KOH} \cdot \mathrm{g}^{-1}\right] \\
\text { Saponification value }\left[\mathrm{mg} \mathrm{KOH} \cdot \mathrm{g}^{-1}\right] \\
\text { Water content }[\%]\end{array}$}} & 0.1 & 0.1 & 65.3 & 68.4 & 47.7 & 201.0 \\
\hline & & & 198.6 & 255.2 & 125.1 & 157.9 & 162.2 & 205.7 \\
\hline & & & 0.11 & 0.10 & 0.55 & 0.34 & 0.37 & 0.16 \\
\hline \multirow{16}{*}{ 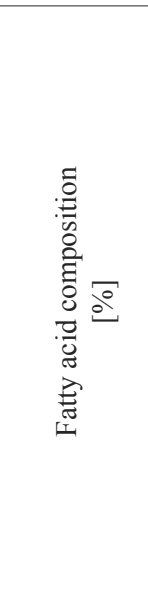 } & Caproic acid & C6:0 & 0.0 & 0.5 & 0.0 & 0.0 & 0.0 & 0.0 \\
\hline & Caprylic acid & $\mathrm{C} 8: 0$ & 0.0 & 6.8 & 0.0 & 0.0 & 0.0 & 0.0 \\
\hline & Capric acid & $\mathrm{C} 10: 0$ & 0.0 & 5.7 & 0.0 & 0.0 & 0.1 & 0.0 \\
\hline & Lauric acid & $\mathrm{C} 12: 0$ & 0.5 & 47.5 & 0.0 & 0.8 & 0.0 & 0.4 \\
\hline & Myristic acid & $\mathrm{C} 14: 0$ & 1.2 & 18.1 & 0.0 & 0.4 & 0.0 & 1.3 \\
\hline & Palmitic acid & $\mathrm{C} 16: 0$ & 43.6 & 9.4 & 7.4 & 12.3 & 11.3 & 49.8 \\
\hline & Palmitoleic acid & C16:1 & 0.0 & 0.0 & 0.0 & 0.0 & 0.0 & 0.2 \\
\hline & Stearic acid & $\mathrm{C} 18: 0$ & 53.8 & 10.8 & 3.4 & 4.1 & 2.5 & 4.1 \\
\hline & Oleic acid & C18:1 & 0.0 & 1.0 & 27.3 & 21.7 & 69.5 & 35.2 \\
\hline & Linoleic acid & C18:2 & 0.0 & 0.0 & 42.4 & 49.7 & 10.9 & 7.8 \\
\hline & Linolenic acid & C18:3 & 0.0 & 0.0 & 1.5 & 6.4 & 0.6 & 0.3 \\
\hline & Arachidic acid & C20:0 & 0.5 & 0.1 & 0.5 & 0.3 & 0.4 & 0.3 \\
\hline & Eicosenoic acid & $\mathrm{C} 20: 1$ & 0.0 & 0.0 & 0.3 & 0.2 & 0.4 & 0.1 \\
\hline & Behenic acid & $\mathrm{C} 22: 0$ & 0.1 & 0.0 & 1.0 & 0.5 & 0.0 & 0.0 \\
\hline & Lignoceric acid & $\mathrm{C} 24: 0$ & 0.1 & 0.0 & 0.5 & 0.2 & 0.1 & 0.0 \\
\hline & Unidentified & & 0.5 & 0.1 & 0.2 & 15.7 & 13.4 & 4.2 \\
\hline \multicolumn{3}{|c|}{ Average alkyl chain carbon quantity } & 17.1 & 13.0 & 17.9 & 17.7 & 17.8 & 16.9 \\
\hline \multicolumn{3}{|c|}{ Average alkyl chain unsaturation quantity } & 0.0 & 0.0 & 1.4 & 1.5 & 1.0 & 0.5 \\
\hline
\end{tabular}

specific melting points of the contained molecules taken from references [65-67]. Physical properties of molecules are given in Table 4.

\subsection{Calculation of solubility parameters}

Molar volumes and molar attraction constants of polylactide and additives were determined according to the van Krevelen and Hoftyzer atomic group contribution method [68]. Average molar volumes and average molar attraction constants of mono, di and triglycerides of oil deodorization condensates were estimated based on average chemical structures previously determined.

Hansen Solubility parameters were calculated using Equations (1), (2) and (3) [69, 70]. Used molar constant values [68] are presented in Table 5:

$\delta_{\mathrm{d}}=\frac{\sum \mathrm{F}_{\mathrm{dt}}}{\sum V_{\mathrm{i}}}$ $\delta_{\mathrm{p}}=\frac{\sqrt{\sum F_{\mathrm{Pi}}^{2}}}{\sum V_{\mathrm{i}}}$

$\delta_{\mathrm{h}}=\frac{\sqrt{\sum E_{\mathrm{hi}}}}{\sum V_{\mathrm{i}}}$

where $\delta_{\mathrm{d}}$ is the dispersion component of the solubility parameter in $\mathrm{J}^{1 / 2} \cdot \mathrm{cm}^{-3 / 2}, \delta_{\mathrm{p}}$ the polar component of the solubility parameter in $\mathrm{J}^{1 / 2} \cdot \mathrm{cm}^{-3 / 2}, \delta_{\mathrm{h}}$ the hydrogen bonding component of the solubility parameter in $\mathrm{J}^{1 / 2} \cdot \mathrm{cm}^{-3 / 2}, F_{\mathrm{d}}$ the dispersion contribution of the molar attraction constant in $\left(\mathrm{J}^{1 / 2} \cdot \mathrm{cm}^{-3 / 2}\right) \cdot \mathrm{mol}^{-1}, F_{\mathrm{p}}$ the polar contribution of the molar attraction constant in $\left(\mathrm{J}^{1 / 2} \cdot \mathrm{cm}^{-3 / 2}\right) \cdot \mathrm{mol}^{-1}, E_{\mathrm{h}}$ the hydrogen bonding energy contribution of the molar attraction constant in $\mathrm{J} \cdot \mathrm{mol}^{-1}$ and $V$ the molar volume contribution of the chemical group involved in $\mathrm{cm}^{3} \cdot \mathrm{mol}^{-1}$.

The solubility of the molecules in PLA (Table 4) was assessed using the HSP Relative Energy Difference (RED) from Equations (4) and (5):

$$
\begin{gathered}
\text { Distance }=\sqrt{4\left(\delta_{\mathrm{d}_{\mathrm{molec}}}-\delta_{\mathrm{dPLA}}\right)^{2}+\left(\delta_{\mathrm{p}_{\mathrm{molec}}}-\delta_{\mathrm{pPLA}}\right)^{2}+\left(\delta_{\mathrm{h}_{\mathrm{molec}}}-\delta_{\mathrm{hPLA}}\right)^{2}} \\
R E D=\frac{\text { Distance }}{\text { Radius }}
\end{gathered}
$$




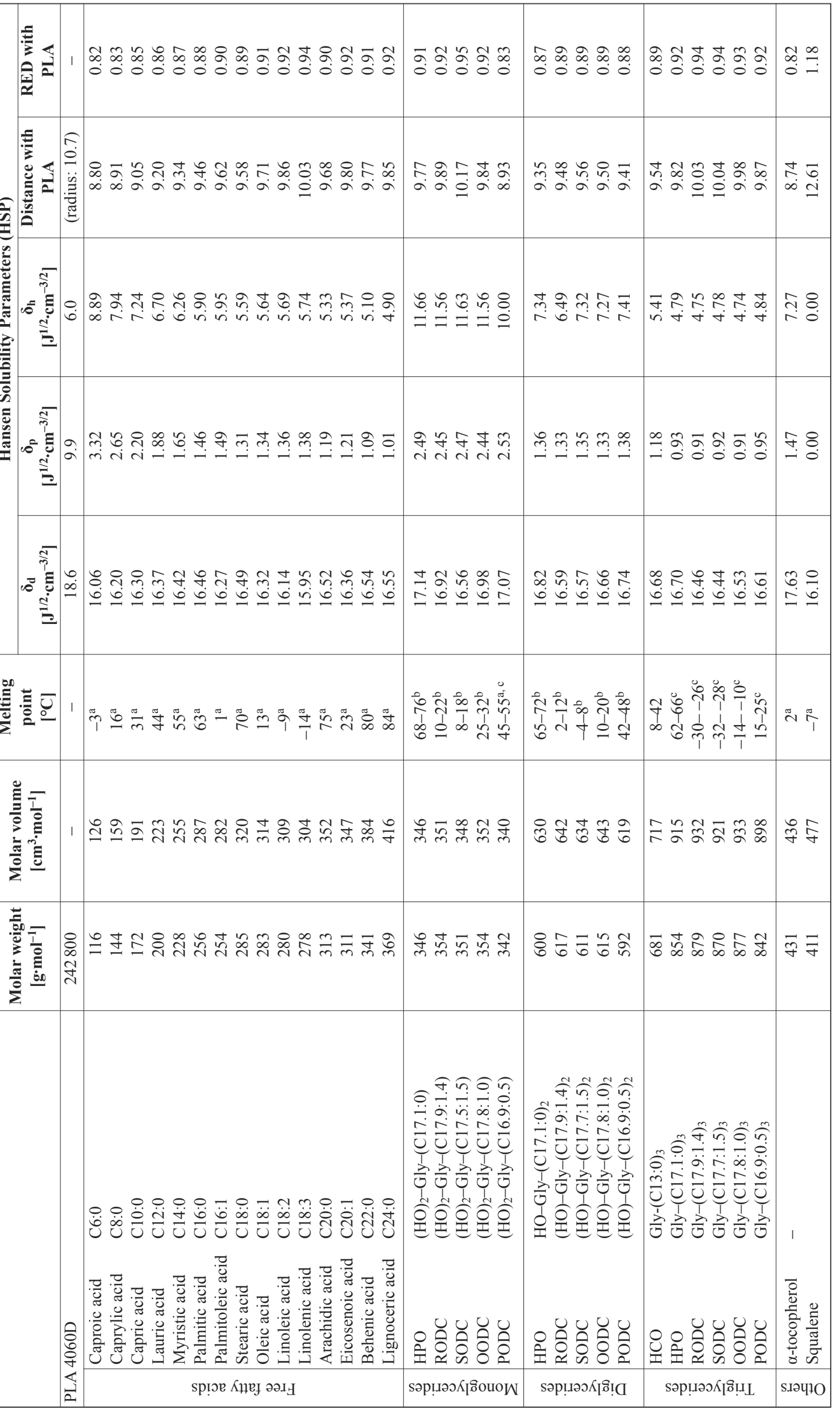


Table 5. Used group contribution molar constants

\begin{tabular}{|c|c|c|c|c|}
\hline Group & $\begin{array}{c}F_{d} \\
{\left[\left(J^{1 / 2} \cdot \mathrm{cm}^{-3 / 2}\right) \cdot \mathrm{mol}^{-1}\right]}\end{array}$ & $\begin{array}{c}\mathbf{F}_{\mathbf{p}}^{2} \\
{\left[\left(\mathbf{J} \cdot \mathrm{cm}^{-3}\right) \cdot \mathrm{mol}^{-1}\right]}\end{array}$ & $\begin{array}{c}\mathbf{E}_{\mathbf{h}} \\
{\left[\mathbf{J} \cdot \mathbf{m o l}^{-1}\right]}\end{array}$ & $\begin{array}{c}\text { Molar volume } \\
{\left[\mathrm{cm}^{3} \cdot \mathrm{mol}^{-1}\right]}\end{array}$ \\
\hline$-\mathrm{CH}_{3}$ & 420 & 0 & 0 & 33.5 \\
\hline$-\mathrm{CH}_{2}-$ & 270 & 0 & 0 & 16.1 \\
\hline$=\mathrm{CH}-$ & 200 & 0 & 0 & 13.5 \\
\hline$>\mathrm{CH}-$ & 80 & 0 & 0 & -1.0 \\
\hline$>\mathrm{C}<$ & -70 & 0 & 0 & -1 \\
\hline$=\mathrm{C}<$ & 70 & 0 & 0 & -5.5 \\
\hline$-\mathrm{COO}-$ & 390 & 240100 & 7000 & 18 \\
\hline$-\mathrm{COOH}$ & 530 & 176400 & 10000 & 28.5 \\
\hline$-\mathrm{OH}$ & 210 & 250000 & 20000 & 10 \\
\hline Ring & 190 & 0 & 0 & 16 \\
\hline
\end{tabular}

where $\delta_{\mathrm{d}}, \delta_{\mathrm{p}}$, and $\delta_{\mathrm{h}}$ are the components of the solubility parameter of the molecules and the PLA obtained from Equations (1), (2) and (3), where the radius value is the maximal distance obtained from [71] beyond which the molecules are not miscible anymore with the polymer. Therefore, the closer the RED value to zero, the better the compatibility. A RED value higher than 1 means a theoretical nonmiscibility of the additive with PLA.

\subsection{Physical-chemical characterization PLA blends}

Differential Scanning Calorimetry (DSC) analyses were performed using a Mettler Toledo (France) DSC1 STARe System under nitrogen atmosphere $\left(50 \mathrm{~mL} \cdot \mathrm{min}^{-1}\right)$ in $40 \mu \mathrm{L}$ standard Aluminum pans (Mettler). Calibration of the device was done using Indium and Zinc standards. Calorimetric scans of additives were performed from -80 to $220^{\circ} \mathrm{C}$ at a heating rate of $2{ }^{\circ} \mathrm{C} \cdot \mathrm{min}^{-1}$. Experiments were carried out in duplicate. Calorimetric scans of blended PLA samples were done at a heating/cooling rate of $10^{\circ} \mathrm{C} \cdot \mathrm{min}^{-1}$. The first heating scan for sample rejuvenation was performed from 25 to $75^{\circ} \mathrm{C}$ with an isotherm at $75^{\circ} \mathrm{C}$ during $2 \mathrm{~min}$. Then, the cooling scan was from 75 to $-20^{\circ} \mathrm{C}$ and the second heating scan from -20 to $100^{\circ} \mathrm{C}$. The glass transition temperature $\left(T_{\mathrm{g}}\right)$ was taken at the midpoint of the second heating scan. Experiments were done in triplicate.

Tensile properties were investigated at $23^{\circ} \mathrm{C}$, relative humidity (RH) $50 \pm 10 \%$ and cross-head speed of $25 \mathrm{~mm} \cdot \mathrm{min}^{-1}$, using an universal tensile machine (Instron model 4301, France) equipped with a load cell $1000 \pm 1 \mathrm{~N}$ and without extensiometer. The dog bone shaped samples (ISO 527-2, type 5A) were directly cut from the materials. Prior to tensile testing, samples were conditioned at $23^{\circ} \mathrm{C}$ and $50 \pm 10 \%$
$\mathrm{RH}$ for at least $72 \mathrm{~h}$. Each mechanical characteristic value is an average of 8 measurements.

Uniaxial deformation under an optical microscope was done in cutting rectangular samples of $20 \mathrm{~mm}$ length, $4 \mathrm{~mm}$ width, and $0.8 \mathrm{~mm}$ thickness from blank PLA, PLA $+10 w t \%$ C16:0, PLA $+10 w t \%$ C18:1 and PLA $+10 \mathrm{wt} \%$ PODC films. They were stretched at $5 \mathrm{~mm} \cdot \mathrm{min}^{-1}$ using a homemade tensile machine placed under an Olympus Japan optical microscope mounted with WHK $10 \times / 20$ L ocular lens and MD Plan 100.25 objective lens. Observations were performed in optical transmission light mode using a Sony CCD-IRIS Model DXC-107P camera (France).

The morphology of the dispersed phase of PLA + $10 \mathrm{wt} \% \mathrm{C} 16: 0, \mathrm{PLA}+10 \mathrm{wt} \% \mathrm{C} 18: 1$ and PLA + $10 \mathrm{wt} \%$ PODC materials before and after being stretched was observed with Scanning Electron Microscopy (SEM) (Hitachi 4800 II, France). Observations were directly conducted on the longitudinal surface of the dog bone shaped samples without any previous preparation.

\subsection{Principal component analysis (PCA)}

PCA was carried out considering the contents of each free fatty acid, mono, di and triglyceride types, hydrocarbons, sterols and water, the acid and saponification values and the measured elongation at break [\%], Young modulus and $T_{\mathrm{g}}$ values of the PLA formulations tested. PCA was done with XLstat software.

\section{Results and discussion}

\subsection{Effects of free fatty acids, glycerides,} $\alpha$-tocopherol and squalene on PLA ductility

Individual components present in vegetable oils, which could feature toughening ability for PLA, as free fatty acids, glycerides, and the unsaponifiable 
components as $\alpha$-tocopherol and squalene were tested. In order to achieve the most efficient formulation, the solubility of a molecule in the polymer matrix is one determinant for its plasticizing power [37]. Therefore the Hansen Solubility Parameters (HSP) of each compound was calculated. HSP (Table 4) shows low solubility of the different compounds in the PLA matrix. All the obtained values are close to one, which marks the solubility limit. The highest solubility (although still modest) was displayed by small fatty acids and $\alpha$-tocopherol. The mechanical and thermal properties of the corresponding compounds are given in Table 6 . The raw data of typical stress/strain curves of blends are presented in Figure 1. The DSC thermograms of neat additives in Figure 2 and of blends in Figure 3 for further information.
Literature studies on the use of vegetable oil as toughening agent of PLA showed that generally chemical modification is required to obtain positive effects [50, 52-54, 56-58, 72]. Not surprisingly due to their low solubility in PLA, the impact of the tested fatty acids (C16:0, C18:1), vegetable oils (HPO and $\mathrm{HCO}$ ) and unsaponifiable compounds on $T_{\mathrm{g}}$ was negligible. However, despite the low solubility of the compounds, PLA ductility was increased in some cases. In particular, HCO, which contains mainly triglycerides, but with short chain length, improved the PLA ductility and lowered the apparent Young modulus, stress and elongation at yield. HPO, which mostly contains triglycerides and some diglycerides with higher chain length did not bring significant ductility enhancement nor $T_{\mathrm{g}}$ decrease. HSP of di- and triglycerides from $\mathrm{HPO}$ and triglycerides from $\mathrm{HCO}$

Table 6. Mechanical and thermal properties of formulations

\begin{tabular}{|c|c|c|c|c|c|c|}
\hline & Formulation & $\begin{array}{c}\text { Elongation at } \\
\text { break } \\
{[\%]} \\
\end{array}$ & $\begin{array}{c}\text { app. Young } \\
\text { modulus }^{\mathrm{a}} \\
\text { [MPa] }\end{array}$ & $\begin{array}{c}\text { Elongation at } \\
\text { yield } \\
{[\%]} \\
\end{array}$ & $\begin{array}{l}\text { Stress at yield } \\
\text { [MPa] }\end{array}$ & $\begin{array}{c}\mathbf{T}_{\mathbf{g}} \\
{\left[{ }^{\circ} \mathbf{C}\right]}\end{array}$ \\
\hline PLA $(\mathrm{t}$ & win screw pellets) & $6 \pm 1$ & $1760 \pm 90$ & $4.2 \pm 0.4$ & $64 \pm 5$ & $56.3 \pm 0.2$ \\
\hline PLA + & $10 \mathrm{wt} \% \mathrm{C} 16: 0$ & $4 \pm 1$ & $1720 \pm 60$ & $3.2 \pm 0.1$ & $50 \pm 3$ & $49.3 \pm 0.1$ \\
\hline PLA + & $10 \mathrm{wt} \% \mathrm{C} 18: 1$ & $16 \pm 5$ & $1440 \pm 50$ & $2.2 \pm 0.1$ & $28 \pm 2$ & $45.2 \pm 0.2$ \\
\hline PLA + & $10 \mathrm{wt} \%[50 \mathrm{wt} \% \mathrm{C} 16: 0+50 \mathrm{wt} \% \mathrm{C} 18: 1]$ & $45 \pm 12$ & $1590 \pm 80$ & $2.2 \pm 0.1$ & $31 \pm 2$ & $40.7 \pm 0.3$ \\
\hline $\begin{array}{r}\text { PLA }+ \\
\text { C18 }\end{array}$ & $\begin{array}{l}10 w t \%[95 w t \%(50 w t \% \text { C16:0 + } 50 w t \% \\
: 1)+5 w t \% \text { HPO }]\end{array}$ & $74 \pm 15$ & $1550 \pm 120$ & $2.2 \pm 0.2$ & $25 \pm 4$ & $39.8 \pm 0.4$ \\
\hline & $5 \mathrm{wt} \% \mathrm{HCO}$ & $9 \pm 3$ & $1680 \pm 70$ & $3.6 \pm 0.2$ & $51 \pm 1$ & $54.1 \pm 0.2$ \\
\hline PLA + & $10 \mathrm{wt} \% \mathrm{HCO}$ & $9 \pm 6$ & $1540 \pm 80$ & $3.6 \pm 0.2$ & $42 \pm 2$ & $54.1 \pm 0.1$ \\
\hline & $15 \mathrm{wt} \% \mathrm{HCO}$ & $11 \pm 5$ & $1460 \pm 70$ & $3.8 \pm 0.2$ & $38 \pm 2$ & $54.8 \pm 0.3$ \\
\hline & $5 \mathrm{wt} \% \mathrm{HPO}$ & $55 \pm 20$ & $1610 \pm 50$ & $2.7 \pm 0.1$ & $38 \pm 1$ & $52.6 \pm 0.2$ \\
\hline PLA + & $10 \mathrm{wt} \% \mathrm{HPO}$ & $85 \pm 15$ & $1420 \pm 70$ & $2.6 \pm 0.2$ & $26 \pm 2$ & $54.4 \pm 0.4$ \\
\hline & $15 \mathrm{wt} \%$ HPO & $91 \pm 14$ & $1300 \pm 80$ & $2.4 \pm 0.1$ & $26 \pm 1$ & $53.9 \pm 0.3$ \\
\hline & $5 \mathrm{wt} \% \alpha$-tocopherol & $6 \pm 2$ & $1150 \pm 90$ & $3.8 \pm 0.2$ & $41 \pm 4$ & $51.3 \pm 0.2$ \\
\hline PLA + & $10 \mathrm{wt} \% \alpha$-tocopherol & $5 \pm 2$ & $1070 \pm 60$ & $4.0 \pm 0.4$ & $31 \pm 3$ & $49.8 \pm 0.2$ \\
\hline & $15 \mathrm{wt} \% \alpha$-tocopherol & $8 \pm 3$ & $990 \pm 70$ & $3.9 \pm 0.3$ & $29 \pm 4$ & $47.1 \pm 0.2$ \\
\hline & $5 \mathrm{wt} \%$ squalene & $38 \pm 7$ & $1180 \pm 90$ & $3.3 \pm 0.4$ & $36 \pm 7$ & $51.4 \pm 0.2$ \\
\hline PLA + & $10 \mathrm{wt} \%$ squalene & $51 \pm 9$ & $990 \pm 60$ & $3.1 \pm 0.9$ & $28 \pm 3$ & $49.5 \pm 0.2$ \\
\hline & $15 \mathrm{wt} \%$ squalene & $29 \pm 7$ & $890 \pm 80$ & $2.9 \pm 0.7$ & $19 \pm 2$ & $49.4 \pm 0.1$ \\
\hline & $5 \mathrm{wt} \%$ RODC & $22 \pm 3$ & $1530 \pm 80$ & $3.2 \pm 0.2$ & $40 \pm 3$ & $52.6 \pm 0.2$ \\
\hline & $10 \mathrm{wt} \%$ RODC & $55 \pm 7$ & $1490 \pm 140$ & $2.4 \pm 0.2$ & $28 \pm 4$ & $49.1 \pm 0.1$ \\
\hline PLA + & $15 \mathrm{wt} \%$ RODC & $65 \pm 15$ & $1380 \pm 155$ & $2.3 \pm 0.3$ & $23 \pm 4$ & $48.8 \pm 0.1$ \\
\hline & $20 \mathrm{wt} \%$ RODC & $73 \pm 20$ & $1270 \pm 150$ & $2.2 \pm 0.3$ & $20 \pm 4$ & $48.5 \pm 0.3$ \\
\hline & $5 \mathrm{wt} \% \mathrm{SODC}$ & $29 \pm 8$ & $1550 \pm 110$ & $3.3 \pm 0.3$ & $41 \pm 7$ & $50.6 \pm 0.1$ \\
\hline & $10 \mathrm{wt} \%$ SODC & $73 \pm 18$ & $1510 \pm 90$ & $2.3 \pm 0.2$ & $25 \pm 5$ & $49.4 \pm 0.3$ \\
\hline PLA + & $15 \mathrm{wt} \%$ SODC & $80 \pm 13$ & $1340 \pm 80$ & $2.2 \pm 0.3$ & $23 \pm 3$ & $48.7 \pm 0.1$ \\
\hline & $20 \mathrm{wt} \%$ SODC & $52 \pm 15$ & $1220 \pm 100$ & $2.1 \pm 0.4$ & $16 \pm 4$ & $47.5 \pm 0.1$ \\
\hline & $5 \mathrm{wt} \%$ OODC & $49 \pm 6$ & $1430 \pm 90$ & $3.1 \pm 0.3$ & $34 \pm 4$ & $49.5 \pm 0.2$ \\
\hline & $10 \mathrm{wt} \%$ OODC & $85 \pm 17$ & $1490 \pm 90$ & $2.6 \pm 0.2$ & $31 \pm 2$ & $49.0 \pm 0.1$ \\
\hline PLA + & $15 \mathrm{wt} \%$ OODC & $88 \pm 16$ & $1360 \pm 70$ & $2.1 \pm 0.2$ & $20 \pm 3$ & $48.5 \pm 0.1$ \\
\hline & $20 \mathrm{wt} \%$ OODC & $67 \pm 16$ & $1370 \pm 110$ & $2.2 \pm 0.2$ & $21 \pm 3$ & $48.7 \pm 0.1$ \\
\hline & $5 \mathrm{wt} \%$ PODC & $51 \pm 17$ & $1680 \pm 110$ & $2.5 \pm 0.2$ & $36 \pm 2$ & $45.3 \pm 0.1$ \\
\hline & $10 \mathrm{wt} \%$ PODC & $132 \pm 18$ & $1460 \pm 40$ & $2.1 \pm 0.2$ & $24 \pm 1$ & $39.2 \pm 0.2$ \\
\hline PLA + & $15 \mathrm{wt} \%$ PODC & $179 \pm 15$ & $1180 \pm 130$ & $2.3 \pm 0.3$ & $18 \pm 2$ & $35.1 \pm 0.2$ \\
\hline & $20 \mathrm{wt} \%$ PODC & $84 \pm 31$ & $1130 \pm 60$ & $2.0 \pm 0.4$ & $14 \pm 3$ & $33.8 \pm 0.2$ \\
\hline
\end{tabular}

${ }^{a}$ apparent Young modulus for comparison reasons obtained without extensiometer 

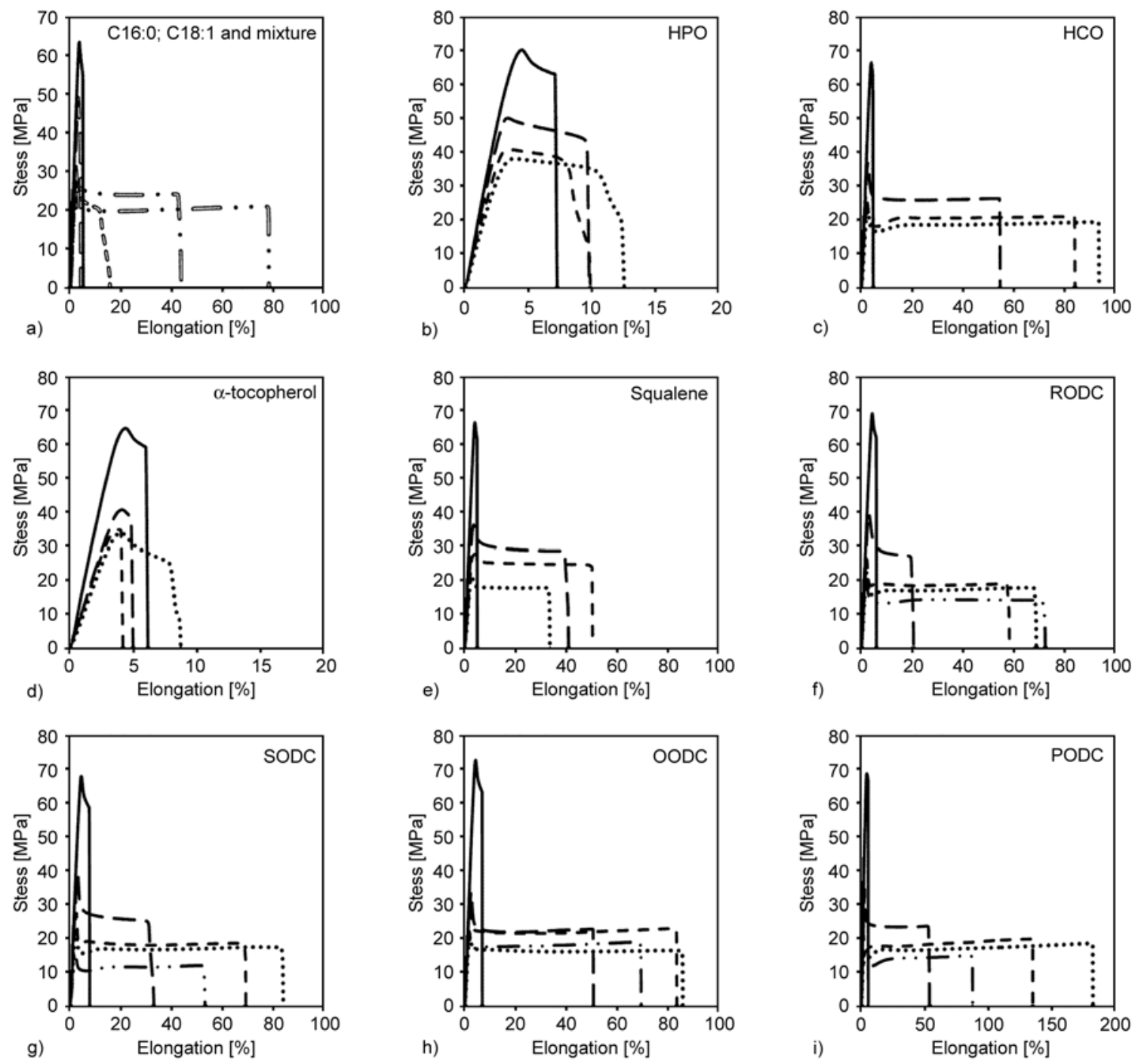

Figure 1. Stress/strain curves of PLA blends with free fatty acids, hydrogenated vegetable oils (HPO and HCO), unsaponifiable compounds (squalene, $\alpha$-tocopherol), and vegetable oil deodorization condensates (palm oil PODC, olive oil OODC, soybean oil SODC and rapeseed oil RODC); (-) neat PLA; (===) PLA + $10 \mathrm{wt} \% \mathrm{C} 16: 0 ;(==)$ PLA + $10 \mathrm{wt} \% \mathrm{C} 18: 1 ;(==\bullet) \mathrm{PLA}+10 \mathrm{wt} \%[50 \mathrm{wt} \% \mathrm{C} 16: 0+50 \mathrm{wt} \% \mathrm{C} 18: 1] ;(==\bullet \bullet) \mathrm{PLA}+10 \mathrm{wt} \%[95 \mathrm{wt} \%(50 \mathrm{wt} \%$ $\mathrm{C} 16: 0+50 \mathrm{wt} \% \mathrm{C} 18: 1)+5 \mathrm{wt} \% \mathrm{HPO}] ;(--)$ PLA $+5 \mathrm{wt} \%$ additive; (- - -) PLA + $10 \mathrm{wt} \%$ additive; (• •) PLA $+15 \mathrm{wt} \%$ additive; (-•) PLA $+20 \mathrm{wt} \%$ additive
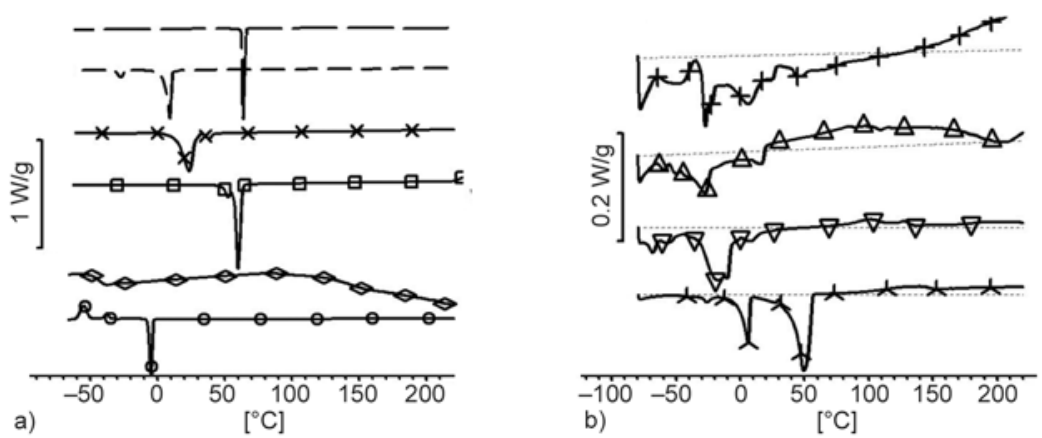

Figure 2. Thermograms (first heating scan) of free fatty acids, hydrogenated vegetable oils (HPO and HCO), unsaponifiable compounds (squalene, $\alpha$-tocopherol), and vegetable oil deodorization condensates (palm oil PODC, olive oil OODC, soybean oil SODC and rapeseed oil RODC); (- - C16:0; (--) C18:1; (×) HCO; ( $\square)$ HPO; ( $\diamond) \alpha$-tocopherol; ( ○) squalene; (+) RODC; ( $\Delta$ ) SODC; ( $\nabla)$ OODC; (^) PODC 

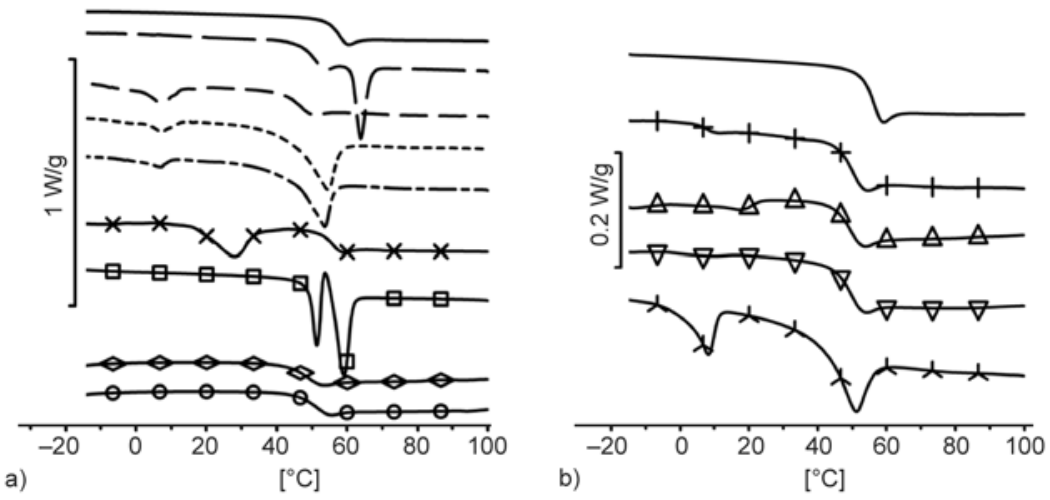

Figure 3. Thermograms (second heating scan) of PLA blends with free fatty acids, hydrogenated vegetable oils (HPO and HCO), unsaponifiable compounds (squalene, $\alpha$-tocopherol), and vegetable oil deodorization condensates (palm oil PODC, olive oil OODC, soybean oil SODC and rapeseed oil RODC); (-) neat PLA; (- - ) PLA + $10 \mathrm{wt} \%$ C16:0; (- -) PLA + $10 \mathrm{wt} \%$ C18:1; (- - -) PLA + $10 \mathrm{wt} \%$ [50 wt \% C16:0 + 50 wt \% C18:1]; (- -) PLA + $10 \mathrm{wt} \%$

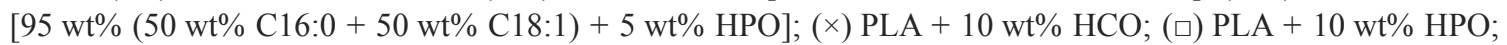
$(\diamond)$ PLA + $10 \mathrm{wt} \% \alpha$-tocopherol; (○) PLA + $10 \mathrm{wt} \%$ squalene; $(+)$ PLA $+10 w t \%$ RODC; $(\Delta)$ PLA $+10 w t \%$ SODC; $(\nabla)$ PLA + $10 \mathrm{wt} \%$ OODC; (ᄉ) PLA + $10 \mathrm{wt} \%$ PODC

were close, while the average molar volume and molecular weight of triglycerides from $\mathrm{HCO}$ are smaller than the ones from HPO (Table 2). Testing of single fatty acids with longer chain length (C16:0, C18:1) showed that they were not able to increase PLA ductility. This is coherent with existing literature. For example, Jacobsen and Fritz [73] studied PLA blends with fatty acid esters. No significant ductility improvement was observed. The blending with the unsaponifiable compound $\alpha$-tocopherol showed small gains in elongation at break, which extends already existing knowledge. It was already shown that the use of $\alpha$-tocopherol as a natural antioxidant in PLA at small quantities $(<4 \mathrm{wt} \%)$ induced a slightly $T_{\mathrm{g}}$ decrease [74] but no increase in elongation at break [75]. Here, no elongation at break improvement upon was found using greater $\alpha$-tocopherol amounts, despite solubility was assessed to be higher than other molecules (such as HPO and HCO, Table 4) and a $T_{\mathrm{g}}$ decrease was observed (Table 3). Squalene, which is a natural tri-terpene found in vegetable oils, showed some toughening abilities (Table 6) despite its low solubility in PLA (Table 4). In fact, the creation of a dispersed phase promoting crazing was most probably responsible for this effect [37].

The most interesting result was obtained upon mixing different compounds. A mix of C18:1 and C16:0 fatty acids increased the PLA ductility much more than using them separately. The Young modulus and the $T_{\mathrm{g}}$ remained higher than using only C18:1 likely because of its lower content involved, while the stress and elongation at yield were lessened as much as adding only $\mathrm{C} 18: 1$. Mixture made of $[95 \mathrm{wt} \%$ $(50 \mathrm{wt} \% \mathrm{C} 16: 0+50 \mathrm{wt} \% \mathrm{C} 18: 1)+5 \mathrm{wt} \% \mathrm{HPO}]$ at a total content of $10 \mathrm{wt} \%$ in PLA, further enhanced the ductility. There was apparently a synergistic effect between compounds, which can be possibly exploited.

\subsection{Properties of PLA blends with vegetable oil deodorization condensates}

Deodorization oil condensates are mixtures of different molecules contained in vegetable oils, the composition of which depends on the botanic source and oil refinery process. Four kinds of oil deodorization condensates (RODC, SODC, OODC and PODC) were blended with PLA, each at four concentrations $(5,10,15$ and $20 \mathrm{wt} \%)$. As shown in Table 3, content in free fatty acids, mono di or triglycerides, sterols (mainly alpha-tocopherol) and hydrocarbons (mainly squalene) was highly variable, as well as unsaturation degree of fatty acids. From the composition, an average HSP was calculated and is given in Table 4. As observed in Table 4, the longer and/or more unsaturated the alkyl chain is, the lower the solubility in PLA. However, except for very short fats alkyl chains and organic compounds as $\alpha$-tocopherol or squalene, HSP of involved molecules appear to be rather similar. Mechanical and thermal properties of PLA/ oil deodorization condensates blends are given in Table 6 and typical curves of raw data are shown in the Figure 1. Significant increases in elongation at break were obtained, especially with the PODC. Addition of too much additive, i.e. about $20 \mathrm{wt} \%$, induced a stagnation or decrease in the elongation at break. All the deodorization condensates led to a 
lowering in the stress and elongation at yield. Interestingly, the apparent Young modulus of materials remained high. The stress/strain curves (Figure 1) showed that the yielding peak shrunk and flattened with the increase in additive content, as if the yield critical stress would tend to meet the plateau value where the stress remains constant with the strain. There is thus an important gain of using native mixtures of fatty acids present in deodorisation condensates for PLA ductility increase.

\subsection{Study of the deformation mechanisms involved in PLA/oil deodorization condensates blends}

In all samples the $T_{\mathrm{g}}$ remained higher than the measurement temperature, the main deformation mechanism was thus crazing of the glassy polymer [37]. The yield process in glassy amorphous polymers can be described as a stress induced glass-transition. In fact, because PLA Poisson's ratio is less than $0.5\left(v_{\mathrm{PLA}}=0.36\right)[76]$, the volume of PLA increases when subjected to tensile stress. Correspondingly, samples experienced important stress whitening, which appeared simultaneously with yielding. Stress whitening is caused by the formation of sizeable microvoids in the polymer matrix due to cavitation and crazes [77]. Crazes can also be initiated inside non-miscible inclusions in the polymer matrix or on the interface between inclusion and polymer in the case of low compatibility. The addition of oil deodorization condensates initiated crazes at stress levels substantially below those of the brittle failure of neat PLA, which propagated perpendicularly to the stretching direction. Morphological analysis of the form and size of inclusions of PODC, C16:0 and C18:1 was done to help interpretation. Figure 4 shows SEM micrographs of [PLA/C16:0], [PLA/ C18:1] and [PLA/PODC] $90 \mathrm{wt} \% / 10 \mathrm{wt} \%$ blends. [PLA/C16:0] blends exhibit rods of about 5 to $10 \mu \mathrm{m}$ length and 1 to $2 \mu \mathrm{m}$ width, corresponding to fatty acid crystals. [PLA/C18:1] showed small spher- ical domains of fatty acids of about $0.5 \mu \mathrm{m}$ diameters and some aggregates of about 3 to $5 \mu \mathrm{m}$ diameters. The [PLA/PODC] blend micrograph showed both rods and aggregates of droplets, where the droplets appear to be distributed all around the crystals.

Figure 5 shows optical micrographs in transmission mode of stretched samples under the microscope taken at different percentages of elongation. Many small cracks started appear in neat PLA when approaching the yield peak, which is common for glassy amorphous polymers. Addition of C16:0, i.e. rod like crystals, increased both the occurrence and the length of cracks. Cracks quantity upon stretching caused the material to become opaque.

Failure of the blend revealed PLA fibrils. C18:1, i.e. small spherical liquid domains, induced fewer but much larger cracks as if their extensibility was eased. PODC, i.e. mostly a combination of C16:0 and C18:1 and some minor constituents, showed a high number of cracks but with smaller width as if using only C18:1. The mixture of palmitic acid crystals and liquid inclusions of oleic acid had thus a synergistic effect allowing for efficient craze initiation by the crystals and by cavitation inside the liquid inclusions. The superior performance of the PODC blends seems thus to be linked to the chemical composition in fatty acids and the presence of the minor constituents.

\subsection{Role of the chemical composition of deodorization condensates in PLA ductility improvement}

A Principal Components Analysis (PCA) was carried out including composition data and physicochemical characteristics of the deodorization condensates and of the PLA samples. Figure 6 shows the principal components projection plot of $\mathrm{F} 1$ and F2 of the data set. Only $50 \%$ of the total variance in these PLA samples is extracted according to F1 and F2 axes. In fact, scores of formulations containing

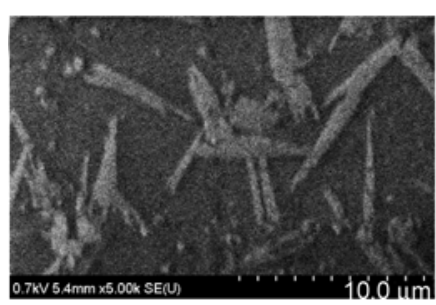

a)

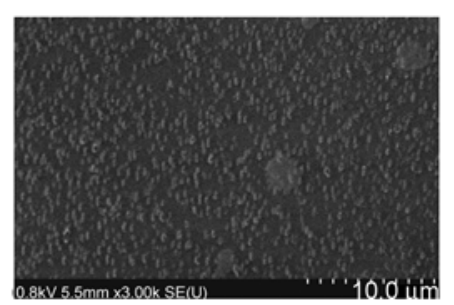

b)

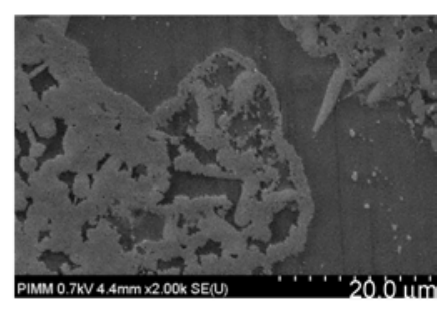

c)

Figure 4. SEM micrographs of (a) C16:0, (b) C18:1 and (c) PODC blends with PLA at 10 wt\% 


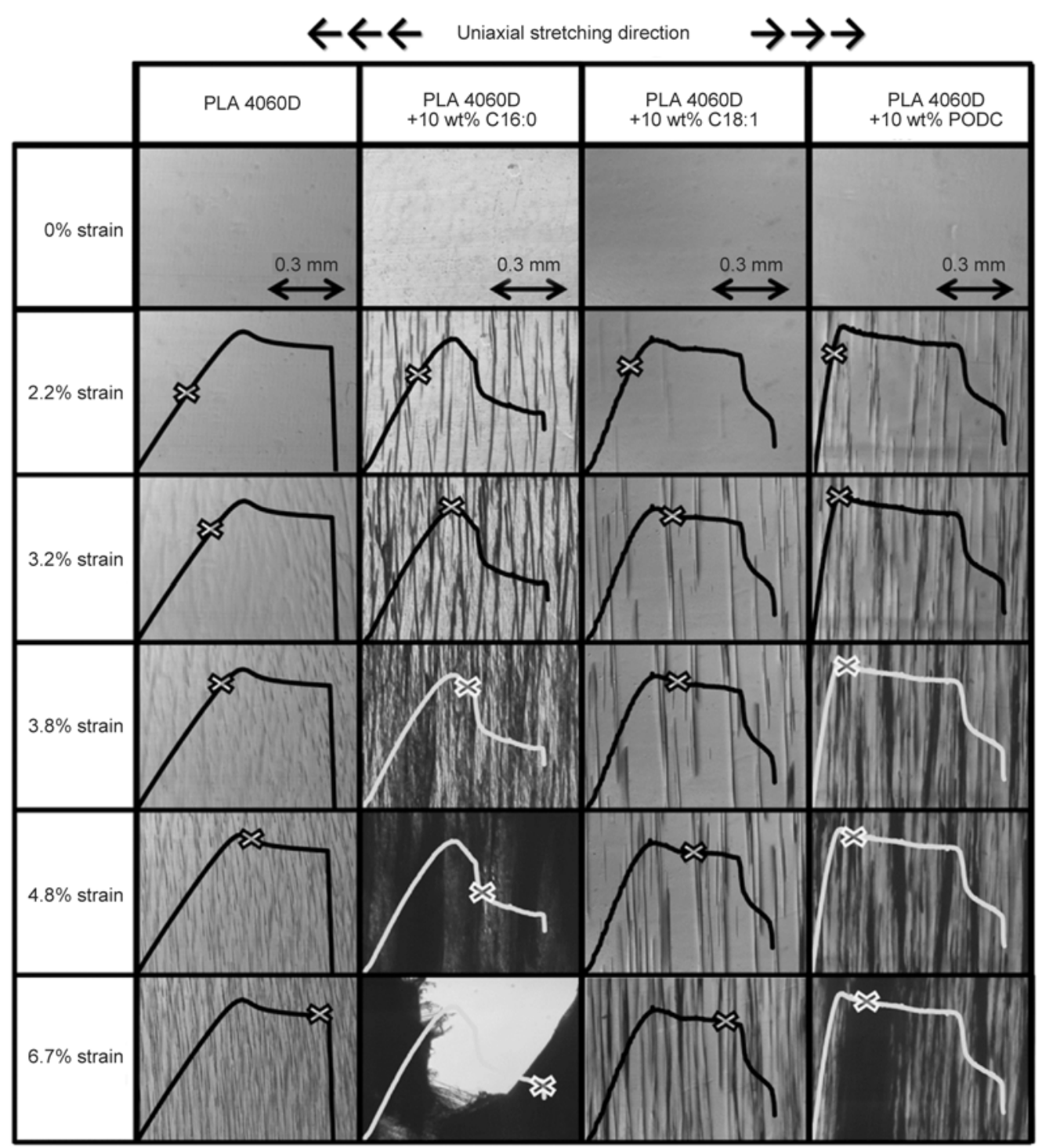

Figure 5. Optical micrographs of uniaxially stretched PLA and PLA blends with free fatty acids (C16:0, C18:1) and palm oil deodorization condensate (PODC) at different strain

squalene, $\alpha$-tocopherol, HPO, HCO and mixtures of C16:0, C18:1 and HPO are not discriminated. However discrimination of PLA samples containing deodorization condensates of each kind of vegetable oils and according to their respective amount is obtained. Corresponding loadings are plotted in Figure 7. The positive part of F1 axis appears to be mainly governed by the elongation at break and as opposed to its negative part with the $T_{\mathrm{g}}$. The F2 axis mostly separates fats as a function of the unsaturation and length of their alkyl chains. Looking at the elongation at break improvement, unsaturation of alkyl chains appears to be required, but the lower the ratio, the larger the enhancement was. Medium alkyl chain length, i.e. from lauric $(\mathrm{C} 12)$ to stearic (C18) acid, also tends to be preferable than the long

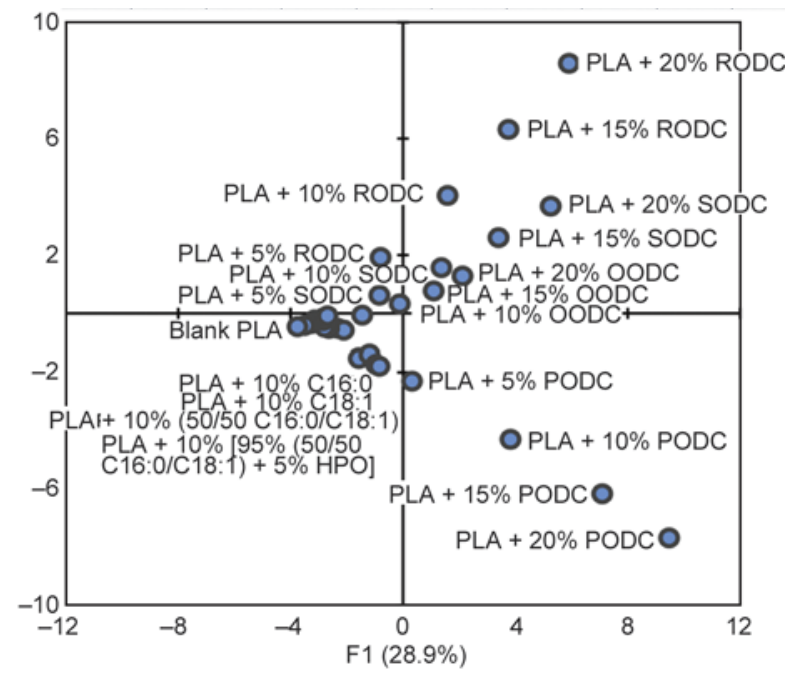

Figure 6. Principal components projection plot of $\mathrm{F} 1$ and F2 of the data set 


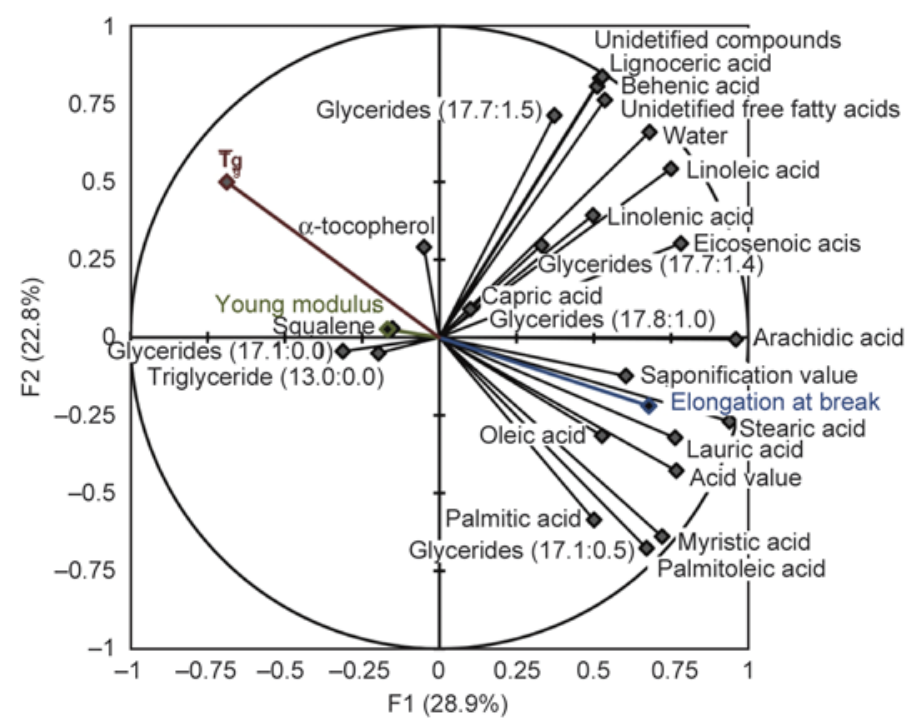

Figure 7. Loadings plot of the Principal Components Analysis of the dataset

ones as behenic (C22) or lignoceric (C24) acids. Both the unsaturation and the length of alkyl chains are main physical factors governing the melting point of fats. One common point is that unsaturation decreases melting points while length increases it. Therefore, efficiency of fats in toughening PLA appeared to be linked to medium melting point properties. A mixture of crystalline and liquid fatty acids at room temperature seemed favorable. This could explain the ability of $\mathrm{HCO}$ triglycerides to increase the PLA ductility while HPO did not, although their HSP were similar, as their ability to depress the $T_{\mathrm{g}}$ of PLA. In fact, due to short alkyl chains, $\mathrm{HCO}$ triglycerides are waxy at room temperature. The DSC thermogram (Figure 2) shows a broad melting peak going from 8 to $42^{\circ} \mathrm{C}$ of $\mathrm{HCO}$ while it is beyond $55^{\circ} \mathrm{C}$ for HPO. Literature shows that combining liquid and solid additives can sometimes be effective for PLA [78]. Acid and saponification values are related to the elongation at break improvement (Figure 7). Therefore, the higher the esterified fats and/or the free fatty acid contents, the better the efficiency of the additive. In opposite, unidentified compounds, i.e. mostly unsaponifiable compounds, are not favorable to the ductility increase. Therefore, the superiority in toughening abilities of the PODC compared to the alike mixture made of $[95 \mathrm{wt} \%(50 \mathrm{wt} \% \mathrm{C} 16: 0+50 \mathrm{wt} \% \mathrm{C} 18: 1)$ $+5 \mathrm{wt} \% \mathrm{HPO}]$ can be attributed to the complex and favorable mixture of fatty acids having different chain length.

\section{Conclusions}

By-products of the vegetable oils industry, namely deodorization condensates, were investigated as biobased additives for ductility improvement of PLA. The deodorization condensates improved substantially the elongation at break of PLA up to $180 \%$. The glass transition was merely decreased which brought ductility to the still glassy polymer. The deformation mechanism was efficient craze initiation delaying failure. Most importantly, it was shown that the industrial by-product of the palm oil refinery had superior properties compared to mixtures of fatty acids and vegetable oils because it contained a mixture of fatty acids with melting points below and beyond room temperature. This makes deodorization condensates efficient and low price additives for PLA able to be used in commodity applications such as food packaging.

\section{Acknowledgements}

This work was supported by Brodart Packaging and the BIP-ADEME French project CREABioM. The authors greatly thank the laboratory Institut des Corps Gras (ITERG - Bordeaux, France) for its technical support.

\section{References}

[1] Auras R., Harte B., Selke S.: An overview of polylactides as packaging materials. Macromolecular Bioscience, 4, 835-864 (2004).

DOI: $\underline{10.1002 / \mathrm{mabi} .200400043}$ 
[2] Auras R. A., Singh S. P., Singh J. J.: Evaluation of oriented poly(lactide) polymers vs. existing PET and oriented PS for fresh food service containers. Packaging Technology and Science, 18, 207-216 (2005).

DOI: $10.1002 /$ pts.692

[3] Petersen K., Væggemose Nielsen P., Bertelsen G., Lawther M., Olsen M., Nilsson N., Mortensen G.: Potential of biobased materials for food packaging. Trends in Food Science and Technology, 10, 52-68 (1999). DOI: 10.1016/S0924-2244(99)00019-9

[4] Solarski S., Ferreira M., Devaux E., Fontaine G., Bachelet P., Bourbigot S., Delobel R., Coszach P., Murariu M., Da Silva Ferreira A., Alexandre M., Degee P., Dubois P.: Designing polylactide/clay nanocomposites for textile applications: Effect of processing conditions, spinning, and characterization. Journal of Applied Polymer Science, 109, 841-851 (2008). DOI: 10.1002/app.28138

[5] Zhang J-F., Sun X.: Mechanical and thermal properties of poly(lactic acid)/starch blends with dioctyl maleate. Journal of Applied Polymer Science, 94, 1697-1704 (2004). DOI: 10.1002/app.21078

[6] Södergård A., Stolt M.: Properties of lactic acid based polymers and their correlation with composition. Progress in Polymer Science, 27, 1123-1163 (2002). DOI: 10.1016/S0079-6700(02)00012-6

[7] Amass W., Amass A., Tighe B.: A review of biodegradable polymers: Uses, current developments in the synthesis and characterization of biodegradable polyesters, blends of biodegradable polymers and recent advances in biodegradation studies. Polymer International, 47, 89-144 (1998).

DOI: 10.1002/(SICI)1097-0126(1998100)47:2<89:: AID-PI86>3.0.CO;2-F

[8] Kaplan D. L.: Biopolymers from renewable resources. Springer, Heidelberg (1998).

DOI: $10.1007 / 978-3-662-03680-8$

[9] Lowe C.: Preparation of high molecular weight polyhydroxyacetic ester. U.S. Patent 2668162 A, USA (1954).

[10] Gruber P. R., Hall E. S., Kolstad J. J., Iwen M. L., Benson R. D., Borchardt R. L.: Continuous process for the manufacture of lactide and lactide polymers. U.S. Patent 6326458, USA (2001).

[11] Gruber P. R., Hall E. S., Kolstad J. J., Iwen M. L., Benson R. D., Borchardt R. L.: Continuous process for manufacture of lactide polymers with purification by distillation. U.S. Patent 5357035, USA (1994).

[12] Avérous L.: Monomers, polymers and composites from renewable resources. in 'Polylactic acid: Synthesis, properties and applications' Elsevier, Amsterdam, 433-450 (2008).

[13] Siracusa V., Rocculi P., Romani S., Rosa M. D.: Biodegradable polymers for food packaging: A review. Trends in Food Science and Technology, 19, 634-643 (2008). DOI: $10.1016 /$ j.tifs.2008.07.003
[14] Liu H., Zhang J.: Research progress in toughening modification of poly(lactic acid). Journal of Polymer Science Part B: Polymer Physics, 49, 1051-1083 (2011). DOI: $10.1002 /$ polb. 22283

[15] Li Y., Shimizu H.: Toughening of polylactide by melt blending with a biodegradable poly(ether)urethane elastomer. Macromolecular Bioscience, 7, 921-928 (2007). DOI: $10.1002 /$ mabi.200700027

[16] NatureWorks. Technology focus report: Toughened PLA. Ver.3/1/2007 (2007).

[17] Zhang W., Chen L., Zhang Y.: Surprising shape-memory effect of polylactide resulted from toughening by polyamide elastomer. Polymer, 50, 1311-1315 (2009). DOI: $10.1016 /$ j.polymer.2009.01.032

[18] Byrne F., Ward P. G., Kennedy J., Imaz N., Hughes D., Dowling D. P.: The effect of masterbatch addition on the mechanical, thermal, optical and surface properties of poly(lactic acid). Journal of Polymers and the Environment, 17, 28-33 (2009).

DOI: $10.1007 / \mathrm{s} 10924-009-0119-\mathrm{x}$

[19] Murariu M., Da Silva Ferreira A., Degée P., Alexandre M., Dubois P.: Polylactide compositions. Part 1: Effect of filler content and size on mechanical properties of PLA/calcium sulfate composites. Polymer, 48, 26132618 (2007).

DOI: 10.1016/j.polymer.2007.02.067

[20] Murariu M., Da Silva Ferreira A., Duquesne E., Bonnaud L., Dubois P.: Polylactide (PLA) and highly filled PLA - Calcium sulfate composites with improved impact properties. Macromolecular Symposia, 272, 112 (2008).

DOI: $10.1002 /$ masy.200851201

[21] Hughes P. A., Becraft M. L., Opusko S.: Polymeric blend comprising polylactic acid. U.S. Patent 20070255013 A1, USA (2007).

[22] Brulé B., Fine T., Flat J-J., Yasuda M.: Composite based on polylactic acid and polyamide, having improved impact resistance, its manufacturing process and use. World Patent WO2007144543 (2007).

[23] Markarian J.: Biopolymers present new market opportunities for additives in packaging. Plastics, Additives and Compounding, 10, 22-25 (2008).

DOI: $10.1016 / \mathrm{S} 1464-391 \mathrm{X}(08) 70091-6$

[24] Jin H-J., Chin I-J., Kim M-N., Kim S-H., Yoon J-S.: Blending of poly(L-lactic acid) with poly(cis-1,4-isoprene). European Polymer Journal, 36, 165-169 (2000). DOI: 10.1016/S0014-3057(99)00041-5

[25] Li Y., Shimizu H.: Improvement in toughness of poly (L-lactide) (PLLA) through reactive blending with acrylonitrile-butadiene-styrene copolymer (ABS): Morphology and properties. European Polymer Journal, 45, 738-746 (2009).

DOI: $10.1016 /$ j.eurpolymj.2008.12.010

[26] McCarthy S. P., Gross R. A., Ma W.: Polylactic acid based blends. U.S. Patent 5883199 A, USA (1999). 
[27] Baiardo M., Frisoni G., Scandola M., Rimelen M., Lips D., Ruffieux K., Wintermantel E.: Thermal and mechanical properties of plasticized poly(L-lactic acid). Journal of Applied Polymer Science, 90, 1731-1738 (2003).

DOI: 10.1002/app.12549

[28] Ljungberg N., Andersson T., Wesslén B.: Film extrusion and film weldability of poly(lactic acid) plasticized with triacetine and tributyl citrate. Journal of Applied Polymer Science, 88, 3239-3247 (2003). DOI: 10.1002/app.12106

[29] Murariu M., Da Silva Ferreira A., Alexandre M., Dubois P.: Polylactide (PLA) designed with desired end-use properties: 1. PLA compositions with low molecular weight ester-like plasticizers and related performances. Polymers for Advanced Technologies, 19, 636-646 (2008).

DOI: $10.1002 /$ pat.1131

[30] Lemmouchi Y., Murariu M., Dos Santos A. M., Amass A. J., Schacht E., Dubois P.: Plasticization of poly(lactide) with blends of tributyl citrate and low molecular weight poly(D,L-lactide)-b-poly(ethylene glycol) copolymers. European Polymer Journal, 45, 28392848 (2009).

DOI: 10.1016/j.eurpolymj.2009.07.006

[31] Wang R. Y., Wan C. Y., Wang S. F., Zhang Y.: Morphology, mechanical properties, and durability of poly (lactic acid) plasticized with di(isononyl) cyclohexane1,2-dicarboxylate. Polymer Engineering and Science, 49, 2414-2420 (2009).

DOI: $10.1002 /$ pen. 21490

[32] Sierra J., Noriega M., Cardona E., Ospina S.: Relationship between properties, citrate content and postproduction time for a plasticized polylactic acid. in 'Proceedings of ANTEC 2010, Orlando, USA' 127-132 (2010).

[33] Courgneau C., Domenek S., Guinault A., Averous L., Ducruet V.: Analysis of the structure-properties relationships of different multiphase systems based on plasticized poly(lactic acid). Journal of Polymers and the Environment, 19, 362-371 (2011).

DOI: $10.1007 / \mathrm{s} 10924-011-0285-5$

[34] Labrecque L. V., Kumar R. A., Davé V., Gross R. A., McCarthy S. P.: Citrate esters as plasticizers for poly (lactic acid). Journal of Applied Polymer Science, 66, 1507-1513 (1997).

DOI: $10.1002 /($ SICI $) 1097-4628(19971121) 66: 8<1507$ :AID-APP11>3.0.CO;2-0

[35] Ljungberg N., Andersson T., Wesslén B.: Film extrusion and film weldability of poly(lactic acid) plasticized with triacetine and tributyl citrate. Journal of Applied Polymer Science, 88, 3239-3247 (2003). DOI: 10.1002/app.12106

[36] Yu J., Wang N., Ma X.: Fabrication and characterization of poly(lactic acid)/acetyl tributyl citrate/carbon black as conductive polymer composites. Biomacromolecules, 9, 1050-1057 (2008).

DOI: $10.1021 / \mathrm{bm} 7012857$
[37] Ruellan A., Guinault A., Sollogoub C., Ducruet V., Domenek S.: Solubility factors as screening tools of biodegradable toughening agents of polylactide. Journal of Applied Polymer Science, in press (2015).

DOI: $10.1002 / A P P .42476$

[38] Kulinski Z., Piorkowska E., Gadzinowska K., Stasiak M.: Plasticization of poly(L-lactide) with poly(propylene glycol). Biomacromolecules, 7, 2128-2135 (2006). DOI: $10.1021 / \mathrm{bm} 060089 \mathrm{~m}$

[39] Kulinski Z., Piorkowska E.: Crystallization, structure and properties of plasticized poly(L-lactide). Polymer, 46, 10290-10300 (2005). DOI: 10.1016/j.polymer.2005.07.101

[40] Hu Y., Hu Y. S., Topolkaraev V., Hiltner A., Baer E.: Crystallization and phase separation in blends of high stereoregular poly(lactide) with poly(ethylene glycol). Polymer, 44, 5681-5689 (2003). DOI: $10.1016 / \mathrm{S} 0032-3861(03) 00609-8$

[41] Jacobsen S., Fritz H. G.: Plasticizing polylactide - The effect of different plasticizers on the mechanical properties. Polymer Engineering and Science, 39, 13031310 (1999). DOI: $10.1002 /$ pen. 11517

[42] Martin O., Averous L.: Poly(lactic acid): Plasticization and properties of biodegradable multiphase systems. Polymer, 42, 6209-6219 (2001). DOI: $10.1016 / \mathrm{S} 0032-3861(01) 00086-6$

[43] Pillin I., Montrelay N., Grohens Y.: Thermo-mechanical characterization of plasticized PLA: Is the miscibility the only significant factor? Polymer, 47, 4676-4682 (2006).

DOI: $10.1016 /$ j.polymer.2006.04.013

[44] Sheth M., Kumar R. A., Davé V., Gross R. A., McCarthy S. P.: Biodegradable polymer blends of poly(lactic acid) and poly(ethylene glycol). Journal of Applied Polymer Science, 66, 1495-1505 (1997).

DOI: 10.1002/(SICI)1097-4628(19971121)66:8<1495 $\because$ AID-APP10>3.0.CO;2-3

[45] Martino V., Ruseckaite R., Jiménez A.: Thermal and mechanical characterization of plasticized poly $(L$-lactide-co- $D, L$-lactide) films for food packaging. Journal of Thermal Analysis and Calorimetry, 86, 707-712 (2006).

DOI: $10.1007 / \mathrm{s} 10973-006-7897-3$

[46] Martino V. P., Jiménez A., Ruseckaite R. A.: Processing and characterization of poly(lactic acid) films plasticized with commercial adipates. Journal of Applied Polymer Science, 112, 2010-2018 (2009).

DOI: 10.1002/app.29784

[47] Ljungberg N., Wesslén B.: Thermomechanical film properties and aging of blends of poly(lactic acid) and malonate oligomers. Journal of Applied Polymer Science, 94, 2140-2149 (2004).

DOI: $10.1002 / a p p .21100$

[48] Ren Z., Dong L., Yang Y.: Dynamic mechanical and thermal properties of plasticized poly(lactic acid). Journal of Applied Polymer Science, 101, 1583-1590 (2006). DOI: 10.1002/app.23549 
[49] Rahman M., Brazel C. S.: The plasticizer market: An assessment of traditional plasticizers and research trends to meet new challenges. Progress in Polymer Science, 29, 1223-1248 (2004).

DOI: 10.1016/j.progpolymsci.2004.10.001

[50] Robertson M. L., Chang K., Gramlich W. M., Hillmyer M. A.: Toughening of polylactide with polymerized soybean oil. Macromolecules, 43, 1807-1814 (2010). DOI: $10.1021 / \mathrm{ma9022795}$

[51] Gramlich W. M., Robertson M. L., Hillmyer M. A.: Reactive compatibilization of poly(l-lactide) and conjugated soybean oil. Macromolecules, 43, 2313-2321 (2010).

DOI: $10.1021 / \mathrm{ma902449x}$

[52] Ali F., Chang Y-W., Kang S. C., Yoon J. Y.: Thermal, mechanical and rheological properties of poly (lactic acid)/epoxidized soybean oil blends. Polymer Bulletin, 62, 91-98 (2009).

DOI: $10.1007 / \mathrm{s} 00289-008-1012-9$

[53] Xu Y-Q., Qu J-P.: Mechanical and rheological properties of epoxidized soybean oil plasticized poly(lactic acid). Journal of Applied Polymer Science, 112, 31853191 (2009).

DOI: 10.1002/app.29797

[54] Xiong Z., Yang Y., Feng J., Zhang X., Zhang C., Tang Z., Zhu J.: Preparation and characterization of poly(lactic acid)/starch composites toughened with epoxidized soybean oil. Carbohydrate Polymers, 92, 810-816 (2012).

DOI: 10.1016/j.carbpol.2012.09.007

[55] Al-Mulla E. A. J., Suhail A. H., Aowda S. A.: New biopolymer nanocomposites based on epoxidized soybean oil plasticized poly(lactic acid)/fatty nitrogen compounds modified clay: Preparation and characterization. Industrial Crops and Products, 33, 23-29 (2010). DOI: $10.1016 /$ j.indcrop.2010.07.022

[56] Silverajah V. S. G., Ibrahim N. A., Zainuddin N., Yunus W., Abu Hassan H.: Mechanical, thermal and morphological properties of poly(lactic acid)/epoxidized palm olein blend. Molecules, 17, 11729-11747 (2012).

DOI: $10.3390 /$ molecules171011729

[57] Silverajah V. S. G., Ibrahim N. A., Yunus W., Abu Hassan H., Woei C. B.: A comparative study on the mechanical, thermal and morphological characterization of poly(lactic acid)/epoxidized palm oil blend. International Journal of Molecular Sciences, 13, 5878-5898 (2012).

DOI: $10.3390 /$ ijms 13055878

[58] Al-Mulla E. A. J., Yunus W. M. Z. W., Ibrahim N. A. B., Ab Rahman M. Z.: Properties of epoxidized palm oil plasticized polytlactic acid. Journal of Materials Science, 45, 1942-1946 (2010).

DOI: $10.1007 / \mathrm{s} 10853-009-4185-1$

[59] NatureWorks: Technology focus report: Polylactic acid containing fillers and fibres (2007).
[60] Bitinis N., Fortunati E., Verdejo R., Bras J., Kenny J. M., Torre L., Lopez-Manchado M. A.: Poly(lactic acid)/ natural rubber/cellulose nanocrystal bionanocomposites. Part II: Properties evaluation. Carbohydrate Polymers, 96, 621-627 (2013).

DOI: 10.1016/j.carbpol.2013.03.091

[61] Yuan D., Chen K., Xu C., Chen Z., Chen Y.: Crosslinked bicontinuous biobased PLA/NR blends via dynamic vulcanization using different curing systems. Carbohydrate Polymers, 113, 438-445 (2014).

DOI: 10.1016/j.carbpol.2014.07.044

[62] Thepthawat A., Srikulkit K.: Improving the properties of polylactic acid by blending with low molecular weight polylactic acid- $g$-natural rubber. Polymer Engineering and Science, 54, 2770-2776 (2014).

DOI: $10.1002 /$ pen.23835

[63] Ayutthaya W. D. N., Poompradub S.: Thermal and mechanical properties of poly(lactic acid)/natural rubber blend using epoxidized natural rubber and poly (methyl methacrylate) as co-compatibilizers. Macromolecular Research, 22, 686-692 (2014). DOI: $10.1007 / \mathrm{s} 13233-014-2102-1$

[64] Hughes J., Thomas R., Byun Y., Whiteside S.: Improved flexibility of thermally stable poly-lactic acid (PLA). Carbohydrate Polymers, 88, 165-172 (2012).

DOI: 10.1016/j.carbpol.2011.11.078

[65] Bradley J-C., Lang A., Williams A.: Jean-Claude Bradley double plus good (highly curated and validated) melting point dataset (2014).

DOI: $10.6084 / \mathrm{m} 9$.figshare. 1031638

[66] Vereeckeen J., Foubert I., Meeussen W., Lesaffer A., Dewettinck K.: Fat structuring with partial acylglycerols: Effect on solid fat profiles. European Journal of Lipid Science and Technology, 111, 259-272 (2009). DOI: 10.1002/ejlt.200800151

[67] Sato K.: Kinetic aspects in polymorphic crystallization and transformation of fats mixed and dispersed systems. in 'Physical properties of fats, oils, and emulsifiers' (ed.: Widlak N.) The American Oil Chemists Society, Champaign, 33-48 (1999).

[68] Van Krevelen D. W., Te Nijenhuis K.: Cohesive properties and solubility. in 'Properties of polymers' (eds.: Van Krevelen D. W., Te Nijenhuis K.) Elsevier, Amsterdam, 189-228 (2009).

[69] van Krevelen D. W.: Chemical structure and properties of coal. XXVIII. Coal constitution and solvent extraction. Fuel, 44, 229-242 (1965).

[70] Van Krevelen D. W., Hoftyzer P. J.: Practical evaluation of the $[\eta]-M$ relationship. III. Estimation of the exponent A. Journal of Applied Polymer Science, 11, 2189-2200 (1967).

DOI: $10.1002 /$ app.1967.070111109

[71] Abbott S. J.: Chemical compatibility of poly (lactic acid): A practical framework using hansen solubility parameters. in 'Poly(lactic acid): Synthesis, structures, properties, processing, and applications' (eds.: Auras R., Lim L. T., Selke S., Tsuji H.) Wiley, Hoboken, 8393 (2010). 
[72] Robertson M. L., Paxton J. M., Hillmyer M. A.: Tough blends of polylactide and castor oil. ACS Applied Materials and Interfaces, 3, 3402-3410 (2011).

DOI: $10.1021 / \mathrm{am} 2006367$

[73] Jacobsen S., Fritz H. G.: Plasticizing polylactide - The effect of different plasticizers on the mechanical properties. Polymer Engineering and Science, 39, 13031310 (1999).

DOI: $10.1002 /$ pen.11517

[74] Manzanarez-López F., Soto-Valdez H., Auras R., Peralta E.: Release of $\alpha$-tocopherol from poly(lactic acid) films, and its effect on the oxidative stability of soybean oil. Journal of Food Engineering, 104, 508-517 (2011).

DOI: 10.1016/j.jfoodeng.2010.12.029

[75] Hwang S. W., Shim J. K., Selke S. E. M., Soto-Valdez H., Matuana L., Rubino M., Auras R.: Poly(L-lactic acid) with added $\alpha$-tocopherol and resveratrol: Optical, physical, thermal and mechanical properties. Polymer International, 61, 418-425 (2012).

DOI: $10.1002 /$ pi.3232
[76] Jamshidian M., Tehrany E. A., Imran M., Jacquot M., Desobry S.: Poly-lactic acid: Production, applications, nanocomposites, and release studies. Comprehensive Reviews in Food Science and Food Safety, 9, 552-571 (2010).

DOI: $10.1111 / \mathrm{j} .1541-4337.2010 .00126 . \mathrm{x}$

[77] Lampman S.: Fracture and fractography. in 'Characterization and failure analysis of plastics' (ed.: Lampman S.) ASM International, Materials Park, 404-416 (2003).

[78] Notta-Cuvier D., Odent J., Delille R., Murariu M., Lauro F., Raquez J. M., Bennani B., Dubois P.: Tailoring polylactide (PLA) properties for automotive applications: Effect of addition of designed additives on main mechanical properties. Polymer Testing, 36, 1-9 (2014).

DOI: 10.1016/j.polymertesting.2014.03.007 